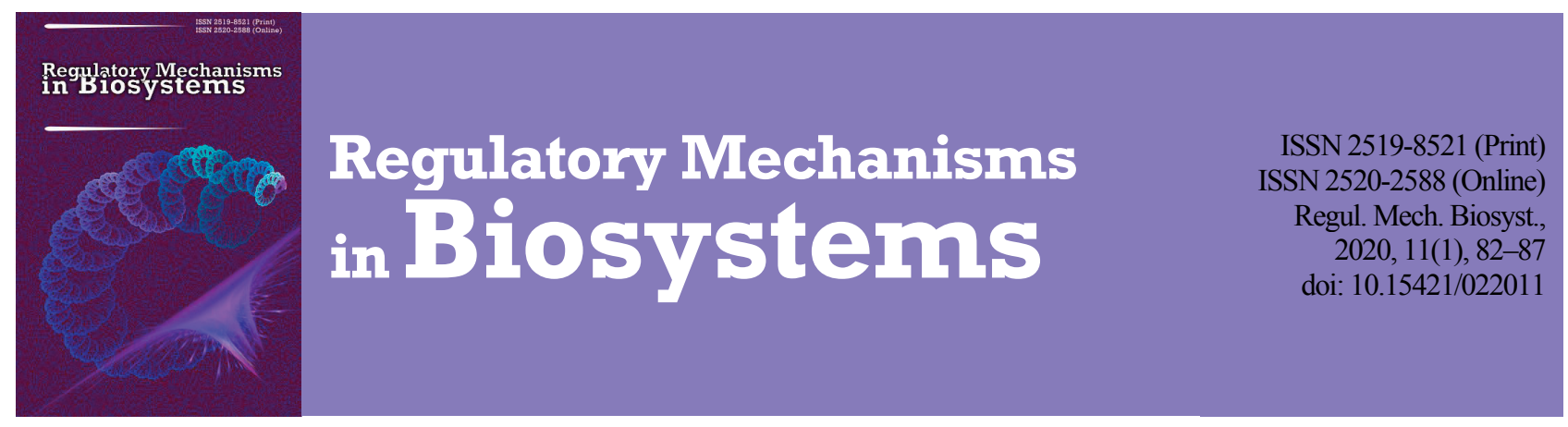

\title{
Sensitivity of antifungal preparations of Candida isolates from sub-biotopes of the human oral cavity
}

\author{
N. O. Osypchuk*, V. B. Nastenko*, V. P. Shirobokov*, Y. V. Korotkyi** \\ *Bogomolets National Medical University, Kyiv, Ukraine \\ **Institute of Organic Chemistry of NAS of Ukraine, Kyiv, Ukraine
}

Article info

Received 04.01.2020

Received in revised form 02.02 .2020

Accepted 03.02.2020

Osypchuk, N. O., Nastenko, V. B., Shirobokov, V. P., \& Korotkyi, Y. V. (2020). Sensitivity of antifungal preparations of Candida isolates from sub-biotopes of the human oral cavity. Regulatory Mechanisms in Biosystems, 11(1), 82-87. doi:10.15421/022011

Bogomolets National Medical University, Taras Shevchenko Boulevard, 13, Kyiv, 01601, Ukraine.

Candidiasis is the commonest opportunistic infection of the oral cavity. As a result of immune-deficiency of the organism, yeasts of Candida genus by acting as commensal organisms transmute into pathogenic organisms. The article presents frequency of isolation, topographic peculiarities, species range, sensitivity of the Candida yeasts to antimycotics and newly-synthesized derivatives of amino alcohols isolated from the sub-biotopes of the oral cavity of patients with oncopathologies. The survey of the material included microscopic, mycologic, statistical-analytical methods. For all the clinical isolates the sensitivity to antifungal preparations was determined. Over the study 492 sub-biotopes of the oral cavity were examined. The extraction of the material was made from the mucous membrane of the cheek, angle of the mouth, mucous membrane of the surface of the tongue and the palate. According to the results of the conducted studies, the level of candidal carriage on the mucous membrane of the oral cavity in the patients with oncopathologies without clinical signs of candidiasis equaled $25.0 \%$, active candidiasis infection was found in $47.0 \%$ of cases. Among the clinical strains, we isolated: . albicans, C. glabrata, C. tropicalis and C. krusei. Among all the isolated strains, in all 4 sub-biotopes C. albicans dominated accounting for $73.1 \%$. In 4 sub-biotopes we detected the association of two species of Candida. Analysis of the obtained results of the susceptibility of strains to modern antymicotics and newly-synthesized substances revealed that the representatives of non-albicans are more resistant to the antifungal preparations. Among the commercial preparations, amphotericin B exerted the highest activity against the clinical isolates of yeast-like fungi. The concentration of $0.97 \mu \mathrm{g} / \mathrm{mL}$ inhibited $50.0 \%$ of representatives of non-albicans, and also $75.0 \%$ of isolates of C. albicans. Fluconazole exhibited activity in the concentration of $1 \mu \mathrm{g} / \mathrm{mL}$ towards $17.0 \%$ of non-albicans and $25.0 \%$ of $C$. albicans. Itraconazole was observed to have no significant antifungal activity. Among the newly-synthesized aryl acyclic amino alcohols, compound Kc22 displayed high activity against both groups of Candida (experimental and control) making it promising for creating new therapeutic preparations. The parameters of resistance of clinical isolates to modern antimycotics indicate the necessity of constant monitoring of the sensitivity of the pathogens of candidiasis and precise species identification for rational use of antifungal preparations and prevention of the development of antimycotic resistance.

Keywords: candidiasis; itraconazole; fluconazole; amphotericin B.

\section{Introduction}

Among the broad diversity of microorganisms, which as representatives of microbiota colonize sub-biotopes of the oral cavity in practically healthy people and patients with different pathological conditions, Archaea, bacteria and eukaryotes are distinguished (Krom et al., 2014; Lof et al., 2017). The oral cavity is an open system to the environment and therefore microorganisms of the oral cavity which are classified as operative taxonomical units (OTUs) will be different in each macroorganism depending on the geographical living location, time of the day of sampling, diet, condition of the immune system (Costalonga et al., 2014). Over the recent decades, fungal diseases have rapidly increased in patients infected by the human immunodeficiency virus (HIV), and in patients receiving intense chemo- and radiation therapy, or prolonged administration of broad-spectrum antibiotics (Aslani et al., 2018; Vipulanandan et al., 2018). The indicated factors have a cytotoxic effect on the immune protective mechanisms of the mucous membrane, change the composition of the microbiota of the oral cavity, causing xerostomia and hyposalivation. Impaired homeostasis of the oral cavity intensifies internal oral colonization, causing fungal infection. Potential pathogenicity for humans is posed by over 100 species of fungi, nosocomial infections are caused by no more than 20 , of which the representatives of the Candida genus prevail (Cho et al., 2014). Candidiasis is an opportunistic infection often diagnosed in patients with oncopathology due to immune-suppression (Aslani et al., 2018; Vipulanandan et al., 2018). The literature sources indicate that the incidence of oral colonization by representatives of Candida ranges $43 \%$ to $90 \%$ among cancer patients (Jain et al., 2016; Aslani et al., 2018).

Candida albicans is the commonest fungus isolated during infections of the oral cavity of practically healthy persons and patients with pathology of different etiology (Montelongo-Jauregui et al., 2018). The studies indicate that in $78.0 \%$ of cases the cause of oral mucositis in cancer patients was $C$. albicans. This species remains the main source of diseases associated with immune suppression, despite the use of antifungal therapy, and can cause systemic infection related to the significant morbidity and mortality (de Sousa et al., 2016; Vaezi et al., 2017). The current tendency to the development of fungemia shows that in most cases this was caused by the species of Candida different from C. albicans, especially among patients of hematological, transplantation and intensive care departments (Taj-Aldeen et al., 2014).

Currently, there is recognition of the role played by species of Candida non-albicans (NACS) in the oral cavity as commensals and etiological agents of infection, including some interactions between different species of yeast-like fungi of the Candida genus (Rossoni et al., 
2015; Barros et al., 2016; Santos et al., 2016). Increase in fungal infections is complicated by increase in the population of patients with weakened immunity. Over recent years this problem has grown with increase in the distribution of C. glabrata and C. tropicalis, which have reduced sensitivity to triazoles, and $C$. krusei, which is naturally resistant to fluconazole and itraconazole (Kathuria et al., 2015; Vipulanandan et al., 2018). Moreover, the development of de novo resistance to triazole among C.albicans limits its therapeutic abilities (Vipulanandan et al., 2018).

Due to reduced sensitivity to polyenes, triazoles and echinocandins, clinical isolates are becoming a serious problem in the therapy of fungal diseases and require accurate species identification.

The objective of the presented work was determining the frequency of isolation, topographic peculiarities, species range, sensitivity of fungi of Candida genus to antibiotics and newly-synthesized derivatives of amino alcohols isolated from the sub-biotopes of the oral cavity of patients with oncopathology.

\section{Materials and methods}

The studies were performed at the Department of Virology and Immunology of the O. O. Bohomolets National Medical University, O. O. Bohomolets Dental Medical Center, National Cancer Institute.

To achieve our goals, we examined a group of 50 oncology patients (experimental group) aged 18 to 78 ( 27 women, 23 men) and 73 practically healthy patients aged 18 to 50 (51 women, 22 men). Among pathologies, we diagnosed: lung cancer (27 patients), mammary gland cancer ( 8 patients), stomach cancer ( 9 patients), esophagus cancer (6 patients). Over the study, the examined patients received chemotherapy (26 patients), a complex of radiotherapy and chemotherapy ( 7 patients), 11 patients underwent surgical treatment, 6 patients were diagnosed for the first time. In total, 492 sub-biotopes of the oral cavity were examined (200 - experimental group, 292 - control). We isolated 218 isolates (101 - experimental group; 117 - control).

The sensitivity of isolates towards the derivatives of alkyl (aryloxyethoxy) dialkylaminopropanol of the general formula:

$$
\mathrm{R}_{1} \mathrm{O}\left(\mathrm{CH}_{2}\right)_{\mathrm{n}} \mathrm{O} \mathrm{V}_{\mathrm{R}_{4}}^{\mathrm{OH}} \stackrel{\mathrm{N}}{+\mathrm{R}_{3}}
$$

where $\mathrm{R}_{1^{-}}$4-(1.1.3.3-tetramethylbutyl)phenoxy, $\mathrm{R}_{2^{-}}, \mathrm{R}_{3^{-}}-\left(4-\mathrm{CH}_{3} \mathrm{CH}\left(\mathrm{CH}_{2}\right)_{4}\right)$, $\mathrm{R}_{4}$ - benzyl, $\mathrm{n}=2, \mathrm{Kc}-2$;

$\mathrm{R}_{1}$ - 4-(1.1.3.3-tetramethylbutyl)phenoxy, $\mathrm{R}_{2}$ - methyl, $\mathrm{R}_{3}$ - cyclohexyl, $\mathrm{R}_{4}-$ benzyl, $\mathrm{n}=2, \mathrm{Kc}-3$;

$\mathrm{R}_{1}$ - 4-(1.1.3.3-tetramethylbutyl)phenoxy, $\mathrm{R}_{2}, \mathrm{R}_{3}-(\mathrm{CH} 2) 6, \mathrm{R}_{4}$ - benzyl, $\mathrm{n}=2, \mathrm{Kc}-14$;

$\mathrm{R}_{1}$ - 4-(1.1.3.3-tetramethylbutyl)phenoxy, $\mathrm{R}_{2}, \mathrm{R}_{3}$ - (methyl), $\mathrm{R}_{4}$ - (4-Fbenzyl), $\mathrm{n}=2, \mathrm{Kp}-18$;

$\mathrm{R}_{1}$ - 4-(1.1.3.3-tetramethylbutyl)phenoxy, $\mathrm{R}_{2}, \mathrm{R}_{3}$ - (methyl), $\mathrm{R}_{4}$ - (4-methylbenzyl), $\mathrm{n}=2, \mathrm{Kp}-19$;

$\mathrm{R}_{1}$ - 4-(1.1.3.3-tetramethylbutyl)phenoxy, $\mathrm{R}_{2}, \mathrm{R}_{3}$ - (methyl), $\mathrm{R}_{4}$ - (4-Fbenzyl), $\mathrm{n}=0, \mathrm{Kp}-4$;

$\mathrm{R}_{1}$-2.4-ditretbutylphenoxy, $\mathrm{R}_{2}, \mathrm{R}_{3}-\left(\mathrm{CH}_{2}\right)_{4}, \mathrm{R}_{4}-\left(\mathrm{CH}_{2}\right)_{4}, \mathrm{n}=0$, Kp-8;

$\mathrm{R}_{1}$ - 2.4-ditretbutylphenoxy, $\mathrm{R}_{2}, \mathrm{R}_{3}-\left(\mathrm{CH}_{2}\right)_{4}, \mathrm{R}_{4}-$ benzyl, $\mathrm{n}=2$, Kc-15;

$\mathrm{R}_{1}-2$.4-ditretbutylphenoxy, $\mathrm{R}_{2}, \mathrm{R}_{3}-\left(4-\mathrm{CH}_{3} \mathrm{CH}\left(\mathrm{CH}_{2}\right)_{4}\right), \mathrm{R}_{4}$ - benzyl, $\mathrm{n}=$ 2, Kc-16;

$\mathrm{R}_{1}$ - 2.4-ditretbutylphenoxy, $\mathrm{R}_{2}, \mathrm{R}_{3}-\left(\mathrm{CH}_{2}\right)_{6}, \mathrm{R}_{4}-$ benzyl, $\mathrm{n}=2$, Kc-22.

The surveyed compounds were synthesized at the Institute of Chemistry of NAS of Ukraine by Candidate of Chemical Sciences Korotkyi Y. V. For obtaining compounds, target-orientated synthesis was made. We obtained 1-[4-(1.1.3.3-tetramethylbutyl)phenoxy-1-ethoxy]-2.3-epoxypropane in the conditions of intra-phase catalysis $(50.0 \% \mathrm{NaOH}$, tetrabutylammonium chloride, epichlorohydrin). Then, in alcohol solution, this substance interacted with secondary amines, producing 1-[4(1.1.3.3-tetramethylbutyl)phenoxy-1-ethoxy]-3-dialkylamino)-2-propanol. While heating in acetone, this substance was treated (isopropanol, acetonitrile) with halogenos alkyls, producing final compounds (Korot- kiy \& Smertenko, 2013). As commercial preparations, we compared amphotericin B and derivatives of azoles (fluconazole, itraconazole).

The material was collected from four sub-biotopes of the oral cavity: the mucous membrane of the cheek (retromolar area), dorsal surface of the tongue, angle of the mouth (border of the mucous membrane and skin), area of the palate. The material was collected using sterile cotton swabs on wooden sticks. The studied biological material was inoculated onto the Sabouraud agar with addition of antibiotic (levomycetin in the concentration of $0.05 \mathrm{~g} / \mathrm{L}$ ) and cultivated at $30^{\circ} \mathrm{C}$ over 5 days. Pure culture of fungi was inoculated to Petri dishes with potato carrot agar and rice agar and incubated for 3 days at the temperature of $37^{\circ} \mathrm{C}$. During the growth, we observed formation of chlamydospores which are a distinctive feature of $C$. albicans. Pure culture was inoculated onto the chromogenic agar for selective isolation of yeasts and direct identification (HiCrome Candida Agar). After $48 \mathrm{~h}$, at the temperature of $37^{\circ} \mathrm{C}$ the colonies of $C$. albicans were light-green; C. tropicalis - light-blue, C. krusei - white, $C$. glabrata - pink. Parallel identification was conducted using test-systems ID 32 test strips manufactured by bioMerieux company, France.

To determine the adhesive properties of the cultures isolated from the sub-biotopes of the oral cavity, we used generally used the method introduced by Brilis et al. (1986). The method involves formalinized erythrocytes of humans with 0 (I) group of blood with positive Rh which is maximally approximated to the model of live structures of the human organism. The advantages of this method is complete in vivo correlation of the results with adhesion, because the survey on adhesion is conducted on cells of human origin; simplicity of obtaining erythrocytes in required amounts; a possibility of surveying a large number of the cultures, and performing express-analysis.

The erythrocytes were formalinized as follows: to fresh defibrinated human blood with $\mathrm{Rh}$ positive 0 (I) group diluted with normal saline $(\mathrm{pH} 7.2$ ) in the proportion (1:1) we added a mixture comprising $20 \mathrm{~mL}$ of $40.0 \%$ formalin and $20 \mathrm{~mL}$ of double phosphate buffer $(\mathrm{pH} 7.2)$. These components were accurately mixed and incubated at the temperature of $37^{\circ} \mathrm{C}$ over $2 \mathrm{~h}$, carefully shaken every $15 \mathrm{~min}$. After the incubation the erythrocytes were four times rinsed with normal saline using centrifugation for $10 \mathrm{~min}$ at $1,000 \mathrm{rpm}$. After rinsing, the erythrocytes were suspended in $400 \mathrm{~mL}$ of buffer and kept at $4{ }^{\circ} \mathrm{C}$ for $48 \mathrm{~h}$. The supernatant was decanted, and the sediment was re-suspended in $400 \mathrm{~mL}$ buffer and then again kept at $4{ }^{\circ} \mathrm{C}$ for $48 \mathrm{~h}$. After the repeated sedimentation, $50 \%$ suspension on buffer solution with $1 \%$ formalin was prepared from the sediment of erythrocytes. For preparation of $1 \%$ solution of formalin, we used $2.7 \mathrm{~mL}$ of $37 \%$ of industrial formalin, added $97.3 \mathrm{~mL}$ of phosphate buffer, obtaining $100 \mathrm{~mL}$ of $1 \%$ formalin. Before using erythrocytes, they were rinsed twice with $0.1 \mathrm{M}$ solution of sodium phosphate and centrifuged at 1,000 rpm. On the buffer solution, we prepared the suspension of erythrocytes with concentration of $10^{8}$ cells $/ \mathrm{mL}$. In order to perform the experiment, the surveyed culture was cultivated for $24 \mathrm{~h}$ on Sabouraud agar, and then, using $0.85 \%$ solution of $\mathrm{NaCl}$, suspension of microorganisms was prepared in the concentration of $10^{9}$ cells $/ \mathrm{mL}$. To the test tubes we added $0.5 \mathrm{~mL}$ of suspension of formalinized erythrocytes and $0.5 \mathrm{~mL}$ of the prepared suspension of microorganisms. The mixture was incubated for $30 \mathrm{~min}$ in $37^{\circ} \mathrm{C}$, being periodically shaken. Then, on a microscope slide we prepared a smear, dried it at room temperature, fixated and stained it using the method of Pappenheim. The adhesion was evaluated under the light microscope.

Interpretation of the results was performed based on the index of adhesiveness of microorganisms (IAM). IAM - average number of microbial cells which underwent adhesion on one erythrocyte that took part in the adhesion.

This indicator was calculated using the formula: $\mathrm{IAM}=(\mathrm{AAI} \times$ 100) / PRRBC, where AAI - average adhesive indicator (i.e. average number of microorganisms which attached to one erythrocyte), PRRBCparticipation rate of red blood cells in adhesion (percentage of erythrocytes which had microorganisms that underwent adhesion on their surface). The microorganism consider as non-adhesive when IAM 1.75; low-adhesive 1.76-2.50; average-adhesive 2.51-4.00; and highadhesive when IAM more than 4.00 . 
The research on susceptibility of clinical isolates to antibiotics and newly-synthesized compounds was performed using the micromethod of serial dilutions with the purpose of determining minimum inhibiting concentration (MIC) in liquid growth medium RPMI 1640 (Arendrup et al., 2015). For the experiment, we used daily culture of Candida grown in liquid glucose-containing medium. For the statistical comparison we used reference-strains of C. albicans (ATCC 10231), the obtained C. glabrata (№199) and C. krusei (RN 71062). The etalon strains of microorganism s were obtained in the L. V. Hromashevsky Institute of Epidemiology and Infectious Diseases of the NAS of Ukraine, the D. K. Zabolotny Institute of Microbiology and Virology of NAS of Ukraine.

The minimum inhibiting concentration (MIC) was surveyed using the method of microdilutions in a polystyrene microtiter plate, allowing us to identify the extent of sensitivity of the fungi to the modern antibiotics. First, we prepared the inoculate of the culture according to the McFarland standard equaling $1 \times 10^{4} \mathrm{CFU} / \mathrm{mL}$ in the medium RPMI 1640 (Arendrup et al., 2015). Titering of the solutions was carried out in order to reduce the subsequent dilution in two times. The results were obtained after 24 of incubation in a thermostat. Absence of signs of growth in the well with the highest dilution of the preparation was considered MIC. For the control in the experiment, from such well we took $10 \mathrm{mcL}$ of the medium, diluting it in $90 \mathrm{mcL}$ of normal saline followed by transfer onto the Sabouraud agar and incubation. Absence of signs of growth was considered a positive result.

The results were statistically analyzed using program pack Statistica 8.0 (Statsoft Inc., USA). The data were presented in the form $\mathrm{x} \pm \mathrm{SD}$ ( $\mathrm{x} \pm$ standard deviation). For the comparison of independent selections, we used non-parametric Mann-Whitney $U$ test. The results were considered reliable at values $\mathrm{P}<0.05$.

\section{Results}

Frequency of detecting representatives of Candida genus in the sub-biotopes of the oral cavity of patients with oncopathologies equaled $72.0 \%$. The level of candidal carriage was $25.0 \%$, and $47.0 \%$ were diagnosed as having candidiasis. The level of candidal carriage in the oral cavity among practically healthy patients without clinical signs was $56.4 \%$. Among the representatives of the Candida genus, in the contents of the biotopes of the oral cavity the following were found: C. albicans, C. glabrata, C. krusei, C. tropicalis, both among the strains isolated from patients with oncopathology, and people of the control group. Among the strains of the control group, $76.0 \%$ were $C$. albicans, $12.8 \%-$ C. glabrata, $10.3 \%-$ C. krusei, $0.9 \%-$ C. tropicalis. Among the isolated clinical isolates, $70.3 \%$ were $C$. albicans, $9.9 \%-C$. glabrata, $12.9 \%$ - C. krusei, 6.9\% - C. tropicalis (Table 1).

Table 1

Species range of yeast-like fungi of Candida genus isolated from the examined patients (\%)

\begin{tabular}{lrrrrrrrr}
\hline & \multicolumn{8}{c}{ Sub-biotopes of the oral cavity } \\
\cline { 2 - 9 } Species & $\begin{array}{c}\text { surface of the } \\
\text { tongue }\end{array}$ & $\begin{array}{c}\text { mucous membrane } \\
\text { of the cheek }\end{array}$ & $\begin{array}{c}\text { zone of the } \\
\text { palate }\end{array}$ & \multicolumn{2}{c}{$\begin{array}{c}\text { angle of the } \\
\text { mouth }\end{array}$} \\
\cline { 2 - 10 } & \multicolumn{1}{c}{$\mathrm{E}^{*}$} & \multicolumn{1}{c}{$\mathrm{C}^{*}$} & \multicolumn{1}{c}{$\mathrm{E}$} & $\mathrm{C}$ & \multicolumn{1}{c}{$\mathrm{E}$} & \multicolumn{1}{c}{$\mathrm{C}$} & \multicolumn{1}{c}{$\mathrm{E}$} & \multicolumn{1}{c}{$\mathrm{C}$} \\
\hline C. albicans & 60.0 & 73.3 & 77.3 & 80.6 & 69.6 & 71.4 & 81.0 & 77.3 \\
C. glabrata & 14.3 & 15.6 & 4.6 & 8.3 & 8.7 & 21.4 & 9.5 & 9.1 \\
C. tropicalis & 8.6 & 0.0 & 9.1 & 0.0 & 8.7 & 7.2 & 0.0 & 0.0 \\
C. krusei & 17.1 & 11.1 & 9.1 & 11.1 & 13.0 & 0.0 & 9.5 & 13.6 \\
$\quad$ Total & 100.0 & 100.0 & 100.0 & 100.0 & 100.0 & 100.0 & 100.0 & 100.0 \\
\hline
\end{tabular}

Note: E - experimental group (patients with oncopathologies), $\mathrm{C}$ - control group (practically healthy patients).

Highest level of Candida colonization among the sub-biotopes in patients with oncopathologies was observed on the mucous membrane of the wall of the tongue (Fig. 1).

During research on the posterior wall of the tongue in cancer patients, we isolated 33 strains. Out of them, $21(60.0 \%)$ were $C$. albicans, 6(14.3\%)-C. glabrata, 6(14.3\%)-C. krusei, 3 (8.6\%)-C. tropicalis. The parameter of the semination of this sub-biotope equaled $34.7 \%$. In this sub-biotope we observed a singular case of association of C. glabrata and $C$. krusei. In the comparison group, no significant differences were observed. However, in the control group, from the wall of the tongue we isolated $C$. tropicalis. The lowest level of semination was seen in the zone of the palate, equaling $22.8 \%$. From that sub-biotope we isolated 23 strains from the patients with oncopathology, including C. albicans accounting for 16 (69.6\%), C. glabrata - 2 (8.7\%), C. krusei $3(13.0 \%)$, C. tropicalis $-2(8.7 \%)$. Associations of fungi of this species were not observed. The control group was observed to have a much lower level of colonization of the palate. No C. krusei was isolated from practically healthy patients. The level of colonization with fungi of Candida genus was noted on the mucous membrane of the cheek accounting for $21.8 \%$. In that sub-biotope, 22 strains were isolated, including C. albicans equaling 17 (77.3\%), C. glabrata -1 (4.5\%), C. tropicalis -2 (9.1\%), C. krusei - 2 (9.1\%). Association of fungi of this genus was observed in two cases. Fungi $C$. albicans and C. tropicalis were also seen coexisting. In that sub-biotope, among practically healthy people, no C. tropicalis were isolated. In the sub-biotope of the angle of the mouth, the incidence of representatives of Candida genus was 20.8\%. A total of 21 strains was isolated from the patients suffering from oncopathologies, including C. albicans accounting for 17 (81.0\%), C. glabrata - 2 (9.5\%), C. krusei-2 $(9.5 \%)$. We observed a single case of association of C. albicans and C. glabrata. In the control and experimental groups, no strains of C. tropicalis were isolated. Thus, among all the isolated strains, the prevailing one in all the 4 sub-biotopes was $C$. albicans. In 4 sub-biotopes, associations of two species of Candida were found.

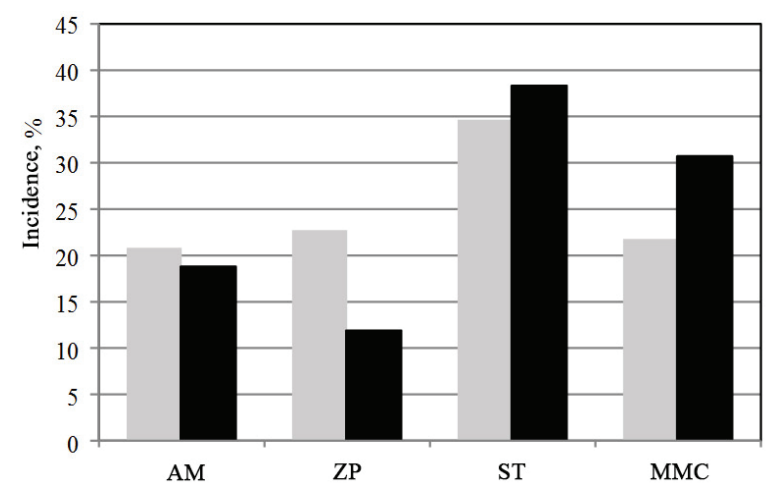

Fig. 1. Incidence of fungi of Candida genus in the sub-biotopes of the oral cavity of the patients with oncopathologies and practically healthy people (AM - angle of the mouth, ZP - zone of the palate, ST - surface of the tongue, $\mathrm{MMC}$ - the mucous membrane of the check) grey - experimental group (patients with oncopathologies),

black - control group (practically healthy people)

The results of evaluation of adhesion revealed that regardless of the sub-biotope the highest parameter of IAM among the clinical strains belonged to $C$. albicans accounting for $3.16 \pm 0.02$. The representatives of non-albicans group exhibited less active ability to adhesion: $C$. tropicalis $-2.45 \pm 0.76$, C. glabrata $-2.51 \pm 0.03$, C. krusei $-2.37 \pm 0.08$.

The survey on the minimum inhibiting concentration of commercial antimycotics and derivatives of alkyl (aryl oxy ethoxy) dialkil-aminopropanol towards clinical isolates of the Candida allowed us to determine the level of activity of this group of preparations against these yeast-like fungi, and thus to compare these indicators with museum strains. The effectiveness of the examined compounds varied depending on the strain and species. The synthesized compounds exerted higher efficiency compared with the commercial preparations. Sensitivity of Candida to the substances and preparations with antimycotic effect was tested towards the representatives of albicans and non-albicans. According to the results of the study, non-albicans displayed higher resistance to this group of preparations (Table 2).

The data demonstrated in Figures 2 and 3 show that the studied substances significantly differed by the level of antimycotic effect against C.albicans and non-albicans. Among the studied newly-synthesized compounds, Kp19 exhibited the highest activity towards the representatives of non-albicans, the concentration of $0.97 \pm 0.71 \mu \mathrm{g} / \mathrm{mL}$ inhibited $83.0 \%$ of the studied strains. Average value of the inhibiting activity of the compound against the museum strain equaled $3.25 \pm 0.65 \mu \mathrm{g} / \mathrm{mL}$. Signifi- 
cant inhibiting effect was exhibited by substances Kc16 and Kc22 which in the same concentration could inhibit $50.0 \%$ of the clinical isolates. Amphotericin B inhibited $17.0 \%$ of strains in the concentration of $0.12 \pm$ $0.07 \mu \mathrm{g} / \mathrm{mL}$, and $50.0 \%$ in $0.97 \pm 0.36 \mu \mathrm{g} / \mathrm{mL}$. A total of $33.0 \%$ of Candida were resistant to the polyene antibiotic. Minimum inhibiting concentration for such strains equaled or was over $31.25 \pm 5.21 \mu \mathrm{g} / \mathrm{mL}$. The lowest efficiency was observed while using fluconazole and itraconazole. The latter exhibited antimycotic effect only in the initial concentration of $1.0 \pm 0.74 \mu \mathrm{g} / \mathrm{mL}$.

Clinical isolates of $C$. albicans were observed to have higher sensitivity to antimycotics. Among the akryl acyclic amino alcohols, the highest activity was demonstrated by compound Kc15. MIC of Kc15 for $42.0 \%$ of strains equaled $0.24 \pm 0.07 \mu \mathrm{g} / \mathrm{mL}$, for $50 \%-0.48 \pm$ $0.14 \mu \mathrm{g} / \mathrm{mL}$. Compound $\mathrm{Kp} 4$ had lower antifungal effect, killing 33.0\% of the strains with the concentration of $0.24 \pm 0.07 \mu \mathrm{g} / \mathrm{mL}$. The concen- tration of $0.48 \pm 0.14 \mu \mathrm{g} / \mathrm{mL}$ exhibited antifungal effect against $58.0 \%$ of Candida. Compounds Kc22, Kc2, Kc3 and Kc16 in the concentrations of $0.48 \pm 0.14 \mu \mathrm{g} / \mathrm{mL}$ displayed antifungal action against $50.0 \%$ of the strains. Against $C$. albicans ATCC 10321, the MIC of the compounds equaled $3.25 \pm 0.65 \mu \mathrm{g} / \mathrm{mL}$ for $\mathrm{Kc} 3$ and $1.30 \pm 0.33 \mu \mathrm{g} / \mathrm{mL}$ for $\mathrm{Kc15}$. These indicators were most efficient regarding the reference strain of microorganism among all the surveyed amino alcohols. The inhibiting effect of Kc22 against the reference strain was $2.60 \pm 0.86 \mu \mathrm{g} / \mathrm{mL}$. Among all commercial antifungal preparations the antifungal effect was exerted by amphotericin B. Activity of this preparation was seen in the concentration of $0.12 \pm 0.3 \mu \mathrm{g} / \mathrm{mL}$. A total of $50.0 \%$ of the strains were inhibited by the dose of $0.48 \pm 0.14 \mu \mathrm{g} / \mathrm{mL}$. Fluconazole in the concentration of $0.97 \pm 0.34 \mu \mathrm{g} / \mathrm{mL}$ killed $25.0 \%$ of strains. To inhibit $50.0 \%$ of clinical isolates, a concentration of over $31.25 \pm 6.11 \mu \mathrm{g} / \mathrm{mL}$ is needed. Antimycotic action of itraconazole took no significant effect.

Table 2

Minimum inhibiting concentration of the derivatives of amino alcohols and antimycotics $(\mu \mathrm{g} / \mathrm{mL}, \mathrm{x} \pm \mathrm{SD}, \mathrm{n}=3, \mathrm{P}<0.05)$

\begin{tabular}{|c|c|c|c|c|}
\hline Preparation & C. albicans ATCC 10231 & C. albicans (clinical strains) & C. non-albicans (reference strains) & C. non-albicans (clinical strains) \\
\hline Kc2 & $1.62 \pm 0.33$ & $5.26 \pm 2.71$ & $9.12 \pm 3.91$ & $16.03 \pm 5.49$ \\
\hline Kc3 & $3.25 \pm 0.65$ & $4.29 \pm 1.73$ & $10.42 \pm 6.51$ & $13.27 \pm 4.67$ \\
\hline Kc14 & $2.92 \pm 0.98$ & $3.92 \pm 1.39$ & $7.81 \pm 3.91$ & $24.09 \pm 9.36$ \\
\hline Kc15 & $1.30 \pm 0.33$ & $4.94 \pm 2.57$ & $9.77 \pm 4.56$ & $34.51 \pm 18.87$ \\
\hline Kc16 & $2.27 \pm 0.87$ & $5.61 \pm 2.71$ & $19.53 \pm 11.72$ & $17.41 \pm 10.21$ \\
\hline Kc22 & $2.60 \pm 0.86$ & $3.11 \pm 1.40$ & $27.35 \pm 6.32$ & $12.12 \pm 6.15$ \\
\hline Kp4 & $2.92 \pm 0.65$ & $8.83 \pm 5.17$ & $23.44 \pm 13.02$ & $29.05 \pm 11.51$ \\
\hline Kp8 & $2.92 \pm 0.98$ & $3.62 \pm 1.36$ & $9.77 \pm 5.86$ & $18.31 \pm 9.94$ \\
\hline Kp19 & $3.25 \pm 0.65$ & $4.04 \pm 0.88$ & $5.86 \pm 3.26$ & $1.70 \pm 1.23$ \\
\hline Fluconazole & $10.4 \pm 2.6$ & $92.8 \pm 43.1$ & $145.8 \pm 62.5$ & $140.8 \pm 74.7$ \\
\hline Amphotericin B & $0.40 \pm 0.08$ & $25.21 \pm 20.62$ & $1.54 \pm 0.84$ & $49.82 \pm 40.34$ \\
\hline Iitraconazole & $145.8 \pm 87.5$ & $895.8 \pm 71.9$ & $302.1 \pm 52.1$ & 1000.0 \\
\hline
\end{tabular}

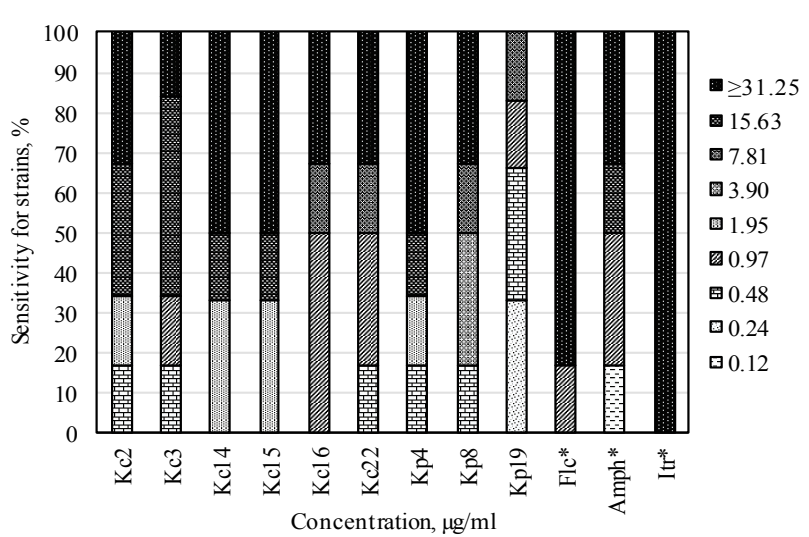

Fig. 2. Sensitivity of $C$. non-albicans to substances with antimycotic effect: Kc2, Kc3, Kc14, Kc 15, Kc16, Kc22, Kp4, Kp8, Kp19-

derivatives of amino alcohols; Flc - fluconazole, Amph B amphotericin B, Itr - itraconazole

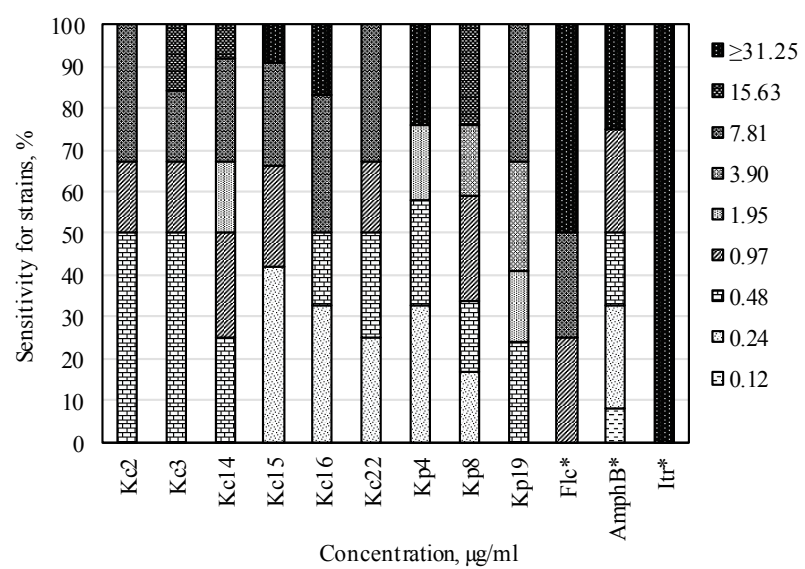

Fig. 3. Sensitivity of $C$. albicans to substances with antimycotic effect: Kc2, Kc3, Kc14, Kc15, Kc16, Kc22, Kp4, Kp8, Kp19-derivatives of amino alcohols; Flc - fluconazole, Amph B - amphotericin B, Itr-itraconazole
Discussion

In the study we observed spread of candidal carriage among practically healthy people, and also a high parameter of candidiasis infection in patients with oncopathologies. Our conclusions coincide with the studies by Jain et al. (2016), Jayachandran et al. (2016). In our population of patients, the level of oral colonization was $72.0 \%$, which corresponds to other similar studies (Aslani et al., 2018). Among the clinical isolates, the prevailing species was $C$. albicans, as well as in the results of surveys by de Sousa et al. (2016), Aslani et al., (2018). In the studies by Jain et al. (2016) the most frequently isolated species was $C$. tropicalis, confirming the theory on spread of the pathogens depending on the geographical locations where patient lives. The main commensal fungus among practically healthy patients was $C$. albicans, correlating with the study by Aslani et al. (2018).

During our studies, we analyzed topographic peculiarities of the colonization of the oral cavity by representatives of Candida. In 4 patients with oncopathology we found associations of fungi. On the mucous membrane of the tongue, we isolated association of C. glabrata and C. krusei, on the mucous membrane of the cheek $-C$. albicans and C. tropicalis, on the mucous membrane of the angle of the mouth $-C$. albicans and C. glabrata. Studies by Tati et al. (2016) indicate that $C$. glabrata is often found in association with $C$. albicans, especially in patients with immune deficiencies. Detected associations of fungi are relevant and require detailed study.

In the study, we found resistance of clinical isolates to fluconazole, correlating with the studies by Badiee et al. (2017), Deorukhkar et al. (2017). All the clinical isolates were resistant to itraconazole, by contrast to the surveys of Zomorodian et al. (2016). Both studies confirm the fact of high resistance of $C$. albicans to itraconazole. The clinical isolates were most susceptible to amphotericin B, as in the surveys by Bagirova \& Dmitrieva (2016).

Currently, a tendency towards spread of the candidiasis is observed, therefore the problem of rational therapy requires great attention (Tkachenko \& Sklyar, 2017). Observations on the dispensary group showed that patients $(63.4 \%)$ with pathogen $C$. albicans were diagnosed with relapse of the disease after 2-3 years. Taking this to account, in cases of relapses of the disease, a combined therapy is used (Glazunov, 2015). This fact indicates necessity of determining the sensitivity of each clinical strain to modern antimycotics. This would allow rational antifungal therapy and 
reduction of the percentage of relapses. One of the possible variants of battling the development of resistance of microorganism is search for new classes of substances with notable antimicrobial action. An example of such compounds can be amino alcohols, derivatives of which exert notable antimicrobial and antifungal activities (Nastenko et al., 2018). We studied the sensitivity of clinical isolates of Candida fungi isolated from subbiotopes of the oral cavity of cancer patients to 9 newly-synthesized derivatives of amino alcohols and determined their antifungal effect. The surveys have confirmed the antimycotic effect of this group of substances (Nastenko et al., 2018). Antifungal effect of this group was studied by Kohdoh et al. (2005). They report that the piperazine propanol derivative GSI578 [(2,6-difluoro-phenyl)-carbamic acid 3-(4-benzothiazol-2-yl-piperazine-1-yl)-propyl ester] was identified as a potent inhibitor against $1,3-\beta$ D-glucan synthase. This enzyme synthesizes the component of the cellular wall of fungus, which is a promising target for antifungal agents. GSI578 exerted in vitro antifungal activity against pathogenic fungi, including C. albicans and Aspergillus fumigatus (Kohdoh et al., 2005). Presence of 4-(1.1.3.3-tetramethylbutyl)phenyl radical was found to be providing the compounds with a broad range of antimicrobial activity. The studies revealed that active compounds belong to III-VI classes of toxicity and cause practically no local irritations $(0.10 \%$ and $0.25 \%$ solutions) (Korotkii et al., 2015). According to the studies by Suvorova (2017), on the model of generalized infection caused by $C$. albicans, KBM-194 (derivative of aryl aliphatic alcohols the compound 1-[4-(1.1.3.3-tetramethylbutyl) phenoxy]-3-(N-benzylhexamethyleneimine)-2-propanol chloride) exerted the most notable effect. In the doses of $0.01 \mathrm{LD}_{50}$ and $0.001 \mathrm{LD}_{50}$ the compound prevents the death of the infected animals, while mortality in the control accounts for $100 \%$.

\section{Conclusion}

According to the results of the preliminary study for the presence of Candida fungi, cases were found in the $72.0 \%$ of patients with oncopathology and in $56.4 \%$ of practically healthy patients. The studies revealed that the incidence of candidal carriage among cancer patients accounted for $25.0 \%$, which was lower than diagnosis of active infection $(47.0 \%)$. Among the clinical isolates, the following were isolated: C. albicans $73.1 \%$, C. glabrata $-8.6 \%$, C. tropicalis $-5.4 \%$, C. krusei $-12.9 \%$. In all the sub-biotopes of both experimental and control groups, the prevailing species was $C$. albicans. The highest level of oral colonization was observed on the surface of the tongue in two groups. The results of evaluating the adhesion show that regardless of the sub-biotope the highest IAM parameter among the clinical strains was produced by C. albicans $-3.16 \pm 0.02$.

Analysis of the obtained results on the sensitivity of strains to modern antimycotics and newly-synthesized substances showed that representatives of non-albicans had higher resistance to antifungal preparations. Among the commercial antifungal preparations, amphotericin B exerted the highest activity against clinical isolates of yeast-like fungi. The concentration of $0.97 \mu \mathrm{g} / \mathrm{mL}$ inhibited $50.0 \%$ of representatives of non-albicans, $75 . \%$ of $C$. albicans isolates. Fluconazole displayed activity in the concentration of $1.0 \mu \mathrm{g} / \mathrm{mL}$ towards $17.0 \%$ of non-albicans and $25.0 \%$ C. albicans. Itraconazole exhibited no significant antifungal activity. Among the newly-synthesized aryl acyclic amino alcohols, Kc22 demonstrated the highest activity against both groups of Candida. These surveys indicate the perspective of using newly-synthesized derivates of amino alcohols in the development of new therapeutic preparations. In spite of spread of the resistance among the clinical isolates to modern antimycotics, rational development of the scheme of therapy in case of active infection requires monitoring of their sensitivity to the preparations and provision of accurate identification of the candidiasis pathogen.

\section{References}

Arendrup, M. C., Cuenca-Estrella, M., Lass-Florl, C., \& Hope, W. (2012). EUCAST technical note on the EUCAST definitive document EDef 7.2: Method for the determination of broth dilution minimum inhibitory concentrations of antifungal agents for yeasts EDef 7.2 (EUCAST-AFST). Clinical Microbiology and Infection, 18(7), 246-247.

Aslani, N., Janbabaei, G., Abastabar, M., Meis, J. F., Babaeian, M., Khodavaisy, S, Boekhout, T., \& Badali, H. (2018). Identification of uncommon oral yeasts from cancer patients by MALDI-TOF mass spectrometry. BMC Infectious Diseases, 18(1), 24

Badiee, P., Badali, H., Boekhout, T., Diba, K., Moghadam, A. G., \& Hossaini, N. A. (2017). Antifungal susceptibility testing of Candida species isolated from the immunocompromised patients admitted to ten university hospitals in Iran: Comparison of colonizing and infecting isolates. BMC Infectious Diseases, 17(1), 727.

Bagirova, N. S., \& Dmitrieva, N. V. (2016). Resistance Candida spp. for amphotericin B in cancer patients. Journal Infectologii, 8(1), 26-31.

Barros, P. P., Ribeiro, F. C., Rossoni, R. D., Junqueira, J. C., \& Jorge, A. O. (2016). Influence of Candida krusei and Candida glabrata on Candida albicans gene expression in in vitro biofilms. Archives of Oral Biology, 64, 92-101.

Brilis, V. I., Brilene, T. A., Lencner, H. P., \& Lencner, A. A. (1986). Metodyka izuchenyia adhezivnogo processa mikroorhanizmov [Methods of studying the adhesive process of microorganisms]. Laboratornoe Delo, 4, 210-212 (in Russian).

Cho, T., Nagao, J., Imayoshi, R., \& Tanaka, Y. (2014). Importance of diversity in the oral microbiota including Candida species revealed by high-throughput technologies. International Journal of Dentistry, 2014, 454391.

Costalonga, M., \& Herzberg, M. C. (2014). The oral microbiome and the immunobiology of periodontal disease and caries. Immunology Letters, 162(2), 22-38.

De Sousa, L. V., Santos, V. L., de Souza, M. A., Dias-Souza, M. V., Marques, S. G., de Faria, E. S., Assunção, E. A. O., Dos Santos, S. G., Zonis, J. M., de Alvarenga, D. G., de Holanda, R. A., de Sousa, J. G., Dos Santos, K. V., \& Stoianoff, M. A. R. (2016). Isolation and identification of Candida species in patients with orogastric cancer: Susceptibility to antifungal drugs, attributes of virulence in vitro and immune response phenotype. BMC Infectious Diseases, 16,86 .

Deorukhkar, S. C., Saini, S., \& Mathew, S. (2014). Virulence factors contributing to pathogenicity of Candida tropicalis and its antifungal susceptibility profile. International Journal of Microbiology, 2014, 456878.

Eddouzi, J., Lohberger, A., Vogne, C., Manai, M., \& Sanglard, D. (2013). Identification and antifungal susceptibility of a large collection of yeast strains isolated in Tunisian hospitals. Medical Mycology, 51(7), 737-746.

Guo, F., Yang, Y., Kang, Y., Zang, B., Cui, W., Qin, B. (2013). Invasive candidiasis in intensive care units in China: A multicentre prospective observational study. Journal of Antimicrobial Chemotherapy, 68(7), 1660-1668.

Jain, M., Shah, R., Chandolia, B., Mathur, A., Chauhan, Y., Chawda, J., Mosby, S., \& Bhagalia, S. (2016). The oral carriage of Candida in oral cancer patients of Indian origin undergoing radiotherapy and/or chemotherapy. Journal of Clinical and Diagnostic Research, 10(2), 17-20.

Jayachandran, A. L., Katragadda, R., Thyagarajan, R., Vajravelu, L., Manikesi, S., Kaliappan, S., \& Jayachandran, B. (2016). Oral candidiasis among cancer patients attending a tertiary Care Hospital in Chennai, South India: An evaluation of clinicomycological association and antifungal susceptibility pattern. Canadian Journal of Infectious Diseases and Medical Microbiology, 8758461.

Kathuria, S., Singh, P. K., Sharma, C., Prakash, A., Masih, A., Kumar, A., Meis, J. F., \& Chowdhary, A. (2015). Multidrug-resistant Candida auris misidentified as Candida haemulonii: Characterization by matrix-assisted laser desorption ionization-time of flight mass spectrometry and DNA sequencing and its antifungal susceptibility profile variability by Vitek 2, CLSI broth microdilution, and Etest method. Journal of Clinical Microbiology, 53(6), 1823-1830.

Kohdoh, O., Inagaki, Y., Fukuda, H., Mizuguchi, E., Ohya, Y., Arisawa, M., Shimma, N., Aoki, Y., Sakaitani, M., \& Watanabe, T. (2005). Piperazine propanol derivative as a novel antifungal targeting 1,3- $\beta$-D-glucan synthase. J-Stage Home, 28(11), 2138-2141.

Korotkii, Y. V., Vrynchanu, N. A., Dronova, M. L., Suvorova, Z. S., \& Smertenko, Z. S. (2015). Synthesis, antibacterial and antifungal activity of 1-[4-(1,1,3,3tetramethylbutyl)phenoxy]-3-dialkylamino-2-propanol quatemary salts. Farmatsevtychnyi Zhurnal, 1, 56-62.

Korotkiy, Y. V., \& Smertenko, O. A., (2013). Patent na korysnu model chetvertynni soli 1-[4-(1,1,3,3-tetrametylbutyl)fenoksi-1-etoksi]-3-(nalkildialkilamino)-2-propanolu. Ukrainian patent for cinnamon model 86109. Fourth salts 1-[4-(1,1,3,3tetramethylbutyl) phenoxi-1-etoxi]-3-(nalkildialkilamino)-2-propanol. Bull. No23 (in Ukrainian).

Krom, B. P., Kidwai, S., \& Ten Cate, J. M. (2014). Candida and other fungal species: Forgotten players of healthy oral microbiota. Journal of Dental Research, 93, 445-451.

Lof, M., Janus, M. M., \& Krom, B. P. (2017). Metabolic interactions between bacteria and fungi in commensal oral biofilms. Journal of Fungi, 3(3), 40.

Montelongo-Jauregui, D., \& Lopez-Ribot, L. (2018). Candida interactions with the oral bacterial microbiota. Journal Fungi, 4(4), 122.

Nastenko, V. B., Korotkiy, Y. V., Smertenko, O. A., Osypchuk, N. O., Shyrobokov, V. P., \& Chobotar, A. P. (2018). Vyvchennia protymikrobnoi aktyvnosti solei alkil (R-aryl) oksydyalkil amoniiu shchodo referentnykh shtamiv mikroorhanizmiv [Study of antimicrobial activity of alkyl (R-aryl) oxy dialkyl ammonium salts towards the reference strains of microorganisms]. Mikrobiologiya i Biotehnologiya, 1, 18-27 (in Ukrainian). 
Nesvizhskiy, Y. V., Volchkova, E. V., Filina, Y. S., Bogdanova, E. A., Umbetova K. T., \& Pak, S. G. (2015). Razrabotka kompleksnoho podkhoda k terapyy ynfektsyy, vyzvannoi hrybamy roda Candida [The elaboration of the complex approach to the treatment of infections caused by fungi of the genus Candida]. Epidemiologiya i Infektsionnye Bolezni, 20(1), 27-31 (in Russian).

Rossoni, R. D., Barbosa, J. O., Vilela, S. F., dos Santos, J. D., de Barros, P. P., Prata, M. C., Anbinder, A. L., Fuchs, B. B., Jorge, A. O., Mylonakis, E., \& Junqueira, J. C. (2015). Competitive interactions between C. albicans, C. glabrata and C. krusei during biofilm formation and development of experimental candidiasis. PLoS One, 10(7), e0131700.

Santos, J. D., Piva, E., Vilela, S. F., Jorge, A. O., \& Junqueira, J. C. (2016). Mixed biofilms formed by $C$. albicans and non-albicans species: A study of microbial interactions. Brazilian Oral Research, 30(1), e23.

Sardi, J. C., Scorzoni, L., Bernardi, T., Fusco-Almeida, A. M., \& Mendes Giannini, M. J. (2013). Candida species: Current epidemiology, pathogenicity, biofilm formation, natural antifungal products and new therapeutic options. Journal of Medical Microbiology, 62(1), 10-24.
Suvorova, Z. (2017). The therapeutic efficacy of 1-[4-(1,1,3,3-tetramethyl butyl) phenoxy]-3-(n-benzyl hexametylenimino)-2-propanol chloride in vivo. ScienceRise: Biological Science, 4, 37-39.

Taj-Aldeen, S. J., Wahab, A., Kolecka, A., Deshmukh, A., Meis, J. F., \& Boekhout, T. (2014). Uncommon opportunistic yeast bloodstream infections from Qatar. Medical Mycology, 5(52), 552-556.

Tati, S., Davidow, P., McCall, A., Hwang-Wong, E., Rojas, I. G., Cormack, B., \& Edgerton, M. (2016). Candida glabrata binding to Candida albicans hyphae enables its development in oropharyngeal candidiasis. PLoS Pathogens, 12(3), e1005522.

Vaezi, A., Fakhim, H., Khodavaisy, S., Alizadeh, A., Nazeri, M., Soleimani, A. Boekhout, T., \& Badali, H. (2017). Epidemiological and mycological characteristics of candidemia in Iran: A systematic review and meta-analysis. Journal de Mycologie Médicale, 27, 146-152.

Vipulanandan, G., Herrera, M., Wiederhold, N. P., Li, X., Mintz, J., Wickes, B. L., \& Kadosh, D. (2018). Dynamics of mixed-Candida species biofilms in response to antifungals. Journal of Dental Research, 97(1), 91-98. 